\title{
LEXICON
}

Volume 6, Number 2

October 2019

https://jurnal.ugm.ac.id/lexicon

Pages 228-237

\section{Turn-Taking Strategies Produced by Male and Female Presenters in American TV Shows}

\author{
Nur Trihandayani Rivai \\ Universitas Negeri Malang, Indonesia \\ Email: nthandayanir@gmail.com
}

\begin{abstract}
This study aims at examining the turn-taking strategies performed by male presenter, Jimmy Kimmel, and female presenter, Ellen DeGeneres, in two American TV talk shows. The data were analyzed using Stenstrom theory (1994) for the turn-taking strategies performed by both presenters. The findings revealed the following. (1) As the representation of male presenters, in conversation with male guests, Jimmy performed most of the strategies such as hesitant start, clean start, uptakes, links, alert, filled pause/ verbal fillers, silent pause, lexical repetition, a new start prompting and appealing. However, he did not apply metacomment and giving up strategy. Furthermore, in conversation with female guests, he used all the strategies, except hesitant start, metacomment, lexical repetition, a new start, and giving up strategy. (2) As the representation of female presenters, Ellen did not use metacomment, silent pause, and giving up strategies in her conversation with male guests. On the other hand, in conversation with female guests, she used all the strategies, except metacomment strategy. (3) This study also revealed that male presenters interrupted more often to female guests than to male guests, which supports the theory proposed by Zimmerman and West (1975).
\end{abstract}

Keywords: gender, turn-taking, turn-taking in gender, Stenstrom theory.

\section{INTRODUCTION}

The ideas of turn-taking have attracted the attention of researchers considering its significance to daily conversation and human behavior (Miller in Beattie, 1982). Many research projects have also shown that social role, age, gender, and background culture are connected to the turn-taking behavior (Laskowski, 2008; Berry, 1994). This idea deals with the role of language in describing and shaping the gender and identity of human beings (Abdelrahim, 2006). If we look at the implications of turn-taking, it can be seen that having research in this area is important and fascinating because it is related to the behavior of human beings.

According to the above points, the present research attempts to investigate the turn-taking strategies used by male and female presenters in talk shows. The presenters who have been chosen as the subject for this research are Jimmy Kimmel, a male famous presenter and comedian, and Ellen DeGeneres who is also a popular female presenter and comedian in America.

Sacks, Schegloff and Jefferson (1974) pioneered a study analyzing turn-taking. They 
provided rules related to turn taking which are: (a) when the next speaker selects the current speaker, the current speaker has the right to speak; (b) if the current speaker does not select the next speaker, anyone can be the next speaker-this is called "selfselection"; (c) if the speaker does not select the next speaker, or there is no "self-selection" then the current speaker can resume his/her turn. In brief, they proposed that a speaker, in face-to-face conversation, can use a number of ways to imply turn-taking.

Related to the study of turn taking, a study conducted by Zimmerman and West (1978) showed that women are lacking in turn taking compared to man. After studying 30 single-sex and mixed-sex conversations, they found that in the 11 mixed-sex conversation, $98 \%$ interruption were made by men. So they conclude that "males assert an asymmetrical right to control topics".

Exploring the issues of gender in turn taking, Fishman (1983) focused her investigation on interruption in private conversations by three hetero-sexual couple in their own house for 14 days. The results showed that men not only interrupted their partners during conversations, but also did not take up their partners' topics in conversations and women failed in trying to start the conversation with the topic they choose. In addition, Elbytra (2014) also came up with similar findings. He analyzed the turn-taking between male and female in the movie "Hitch". One of his major findings showed that women tend to wait until the speakers finish their talk, while men overlap and interrupt the other speaker. However, not only men talk more than women, but women and men tend to talk more in different kinds of situation (Eckert and Mc Connell, 2003).

However, another study asserts that women can do turn-taking as well as the men in the particular time and place. Maghrida (2016) examined how male and female characters performed different turn-taking organization in "Before Midnight" movie, especially in the part when the male and female characters are having arguments. Adopting the theory proposed by Sacks, Schegloff, and Jefferson (1974), the result shows that both male and female characters were similar in the sense of turn allocation: both use 'current speaker select next speaker' and 'self-selection'. And related to gender, female character dominated male since she interrupted more. This is related to Tannen's theory (1992) which stated that female tend to talk freely in a private setting.

Furthermore, turn-taking has been observed in various settings such as debates, speeches, conferences, and talk shows, in formal and informal mode of conversation (Ghilzai, 2015). Talk shows also have become a popular source of data to look at the phenomenon. This is so, in conversation, participants have to confine themselves to the activity, asking questions and giving answers (Hutchby, 2006).

Relating to above points, this study is to analyze the turn-taking strategies used by male and female presenters in Ellen DeGeneres and Jimmy Kimmel talk shows. The research addresses the following questions are:

(1) What turn-taking strategies does Jimmy Kimmel use to male and female guests?

(2) What turn-taking strategies does Ellen DeGeneres use to male and female guests?

\section{THEORETICAL FRAMEWORK}

\section{Conversation Analysis}

The study of conversation and talk-ininteraction wasconducted by Sacks, Jefferson, and Schegloff in late 1960s and the earlier 1970s is called Conversation Analysis (CA) which is also known as an approach in studying conversation in social interaction. According to Liddicoat (2007), "one of the most noticeable features of conversation is that speakers change". Relating to the study of turntaking, CA methods attempt to record and explain how participants can understand to one another's action during their back-and-forth interaction and how they set up their turns to respond to previous turn(s) (Drew, 2005). Furthermore, in analyzing conversation, the researchers collected the data using video or audio recording, then the records aretranscribed to see the patterns of the conversation. The transcription helps the researchers to notice the features of the talk being 
transcribed and to see the detailed aspects that may appear outside the act of transcription (Heath and Luff, 1993).

\section{Turn-Taking Strategies}

Stenstrom (1994) proposes three turn-taking strategies: taking the turn, holding the turn, and yielding the turn.

\section{Taking the Turn}

Taking the turn is the condition when someone is going to take turn in conversation, either to give comment about the current topic or to create a new topic. Based on Stenstrom (1994), there are three ways in taking the turn: starting up, taking over, and interrupting.

\section{1) Starting up}

The starting up strategy is divided into two categories: hesitant start and clean start. Hesitant start happens when the next speaker is not fully prepared to start the conversation. Furthermore, there are two possible ways in starting up, which are filled pauses and verbal fillers. On the other hand, a clean start happens when the current speaker knows what is going to be said because the speaker already prepared for it.

\section{2) Taking over}

Taking over involves uptakes or links. Uptakes strategy happens when the next speaker understands what has been said by the previous speaker and evaluate it before expressing his/her words. Some uptakes that usually used are: yeah, oh, well, no, yes. Moreover, there is also uptakes without appealer

Another strategy for taking over is links. This strategy are known by the use of conjunction in taking the floor such as, and, but, so, and because

\section{3) Interrupting}

Interruption happens when the next speaker abruptly cuts off the current speaker's talk. Furthermore, here are two kinds of interruption: alert and metacomments. Alerts (e.g.: listen, hey, look) happens when the next speaker cuts off the ongoing talk with a higher pitch. Moreover, metacomment (e.g.: can I just tell, may I halt you) is a polite version of interruption. This is usually applied in formal situation.

\section{Holding the Turn}

Holding the turn is one of the strategies for the current speaker to maintain the turn in speaking. There are four strategies in holding the turn: Filled Pause or Verbal Fillers, Silent Pause, Lexical Repetition, and A New Start.

\section{1) Filled Pause or Verbal Fillers}

By using this strategy, the speaker is not trying to give the turn, but attempts to say something. However, the duration of filled pause or verbal fillers cannot be too long because the next speakers will assume that it is their turn.

\section{2) Silent Pause}

One of the ways in maintaining the floor is by applying the silent pause strategy. This strategy is longer than filled pause strategy.

\section{3) Lexical Repetition}

To keep the conversation going, the current speaker may employ lexical repetition strategy. The main feature of this strategy is the use of repetition of the word, clause partial, or the combination of both to maintain the floor.

\section{4) A New Start}

A new start strategy is applied if the current speaker wants to maintain the floor but failed to continue the topic that has been said.

\section{Yielding the Turn}

Giving someone a chance to speak is called yielding the turn. There are three kinds of yielding the turn: prompting, appealing, and giving up. 


\section{1) Prompting}

Apologizing, greeting, inviting, offering, questioning and requesting are the examples of prompting.

\section{2) Appealing}

Appealing means give other people chance to speak in order to get the feedback by using the word such as: alright, you know, you see, and tag question.

\section{3) Giving Up}

Giving up strategy happens when the current speaker realizes that she/he does not have any topic to be told, so he/she give the turn by making a long pause.

\section{Turn-taking in Gender Studies}

Employing the turn-taking model proposed by Sacks, Shegloff, and Jefferson (1994), Coates (2013) pointed out some violations of turn-taking made by men in mixed-sex conversation, based on some well-known research projects. She identified how male grabbing the floor and holding the turn in turn taking-strategies. In grabbing the floor, it shows that males dominate in mixed-sex conversation compared to females (Zimmerman \& West, 1975; Eakins \& Eakins, 1979; Leet-Pellegrini, 1980; Mulac et al. 1988; Schick Case, 1988; Holmes, 1995; Gunnarsson, 1997) even if the female has high status (West, 1998).

Meanwhile, in holding the turn strategy, it shows that males talk a lot more than females. When males were asked to describe three pictures, they took on average 13.00 minutes per picture while females took average 3.17 minutes per picture, more than four time as long (Swacker, 1975). A research from Herring, Johnson, and DiBenedetto (1998), the participants (men and women) were having discussion of 'men's literature' which lasted for five weeks. The results show that men contributed $70 \%$ of the total words. Moreover, during the five weeks, there were two days when women contribution surpassed the men's. However, men were getting angry, assuming they were being 'silenced' and threatening to 'unsubscribe' from the network.

Concerning the detailed explanation above, it shows that men dominate women in mixed-sex conversation and violate the rule of turn-taking, because according to Sacks, Schegloff and Jefferson (1974), the rule of turn-taking is 'at least and not more than one speaker talks at a time'. Participants in conversation are equals and that they have equal rights to the floor (Coates, 2013).

\section{METHODS}

The data were taken from the conversations between presenters and the guests from two talk shows aired in America: Ellen DeGeneres Show and Jimmy Kimmel Live! In every episode, these two talk shows invite two or three guests. However, the the research focused only on certain guests (male and female) who were being interviewed in the same day, specifically one in the afternoon in Ellen DeGeneres Show and another one at midnight in Jimmy Kimmel Live!. The videos of Jimmy Kimmel and Ellen DeGeneres interviewing Anthony Anderson were aired in October $2^{\text {nd }}$ 2017. On the other hand, the videos of Jimmy Kimmel and Ellen DeGeneres interviewing Kate Hudson were aired at October 12 $2^{\text {th }}$ 2017. (See Appendix 1 for a list of the videos used as the data sources in this study.)

First, the data in the form of conversation in the video that had been downloaded was transcribed using Jefferson's transcription convention (1985) (in Liddicoat, 2007). However, in this research, not all of the transcription notations were applied in transcribing the conversation. The notation applies only to some notations related to the strategies in turn-taking proposed by Stenstrom (1994). Then, the conversation in the video were transcribed. After classifying based on the strategies, then I explained the situation that happened between the presenters and the guests to make the readers understand what was actually going on in the conversation. 


\section{RESULTS AND DISCUSSION}

\section{Jimmy Kimmel's Interview with a Male Guest, Anthony Anderson}

Table 1. Frequency of Jimmy Kimmel's turn taking strategies in interview with a male guest

\begin{tabular}{|c|c|c|c|}
\hline Strategy & Substrategy & Freq. & $\%$ \\
\hline \multirow{3}{*}{$\begin{array}{l}\text { Taking } \\
\text { the turn }\end{array}$} & Starting up & 6 & 9.52 \\
\hline & Taking over & 9 & 14.29 \\
\hline & Interrupting & 3 & 4.76 \\
\hline \multirow{4}{*}{$\begin{array}{l}\text { Holding } \\
\text { the turn }\end{array}$} & $\begin{array}{l}\text { Filled } \\
\text { pause/Verbal } \\
\text { fillers }\end{array}$ & 6 & 9.52 \\
\hline & Silent pause & 4 & 6.35 \\
\hline & $\begin{array}{l}\text { Lexical } \\
\text { repetition }\end{array}$ & 1 & 1.59 \\
\hline & A new start & 1 & 1.59 \\
\hline \multirow{4}{*}{$\begin{array}{l}\text { Yielding } \\
\text { the turn }\end{array}$} & Prompting & 31 & 49.21 \\
\hline & Appealing & 2 & 3.17 \\
\hline & Giving up & - & - \\
\hline & Total & 63 & 100.00 \\
\hline
\end{tabular}

The result of the findings showed that Jimmy performed hesitant start, clean start, uptakes, links, alert, filled pause/verbal fillers, silent pause, lexical repetition, a new start, prompting, and appealing in his conversation with a male guest, Anthony Anderson. For example:

\section{(1) Anthony: [oh let's do it] are you guys still} friends

Jimmy: of course

Anthony: okay

Jimmy: by the way I saw mmm I saw you last time at the emmys a couple weeks ago and aaa in fact where I saw you you were on stage very busy presenting the best variety talk series award to another show to john oliver instead to your best friend jim how many times have you been on john oliver's show

As explained in the previous section, hesitant start can be noticed by the use of filled pause in the beginning of the utterance which indicates that the current speaker is not fully prepared in taking the turn. Jimmy started the topic yet hasn't fully prepared for the conversation which indicates that he performed hesitant start strategy by using the filled pause "mmm".

Meanwhile, in holding the turn, he performed silent pause as one of the examples:

(2) Jimmy: but these babies (0.2) you said they're good so they just don't cries

Anthony: they don't cry at all men the best temperament of ofof any infant I've ever work with man they're the happiest babies around.

Furthermore, in yielding the turn, the example is:

(3) Jimmy: did you test the babies before it to make sure they have a good temperament or it was luck that gave you good temperament babies.

Anthony: I I think it was luck because I think parents would bring their babies baby benadryl up to the audition.

Jimmy applied prompting strategy to give the turn to Anthony to speak. Asking question is one of the features in yielding the turn.

\section{Jimmy Kimmel's Interview with a Male Guest, Kate Hudson}

Table 2. Frequency of Jimmy Kimmel's turn taking strategies in interview with a female guest

\begin{tabular}{|c|c|c|c|}
\hline Strategy & Substrategy & Freq. & $\%$ \\
\hline \multirow{3}{*}{$\begin{array}{l}\text { Taking } \\
\text { the turn }\end{array}$} & Starting up & 2 & 4.35 \\
\hline & Taking over & 6 & 13.04 \\
\hline & Interrupting & 16 & 34.78 \\
\hline \multirow{4}{*}{$\begin{array}{l}\text { Holding } \\
\text { the turn }\end{array}$} & $\begin{array}{l}\text { Filled } \\
\text { pause/Verbal } \\
\text { fillers }\end{array}$ & 2 & 4.35 \\
\hline & Silent pause & 1 & 2.17 \\
\hline & $\begin{array}{l}\text { Lexical } \\
\text { repetition }\end{array}$ & - & - \\
\hline & A new start & - & - \\
\hline \multirow{4}{*}{$\begin{array}{l}\text { Yielding } \\
\text { the turn }\end{array}$} & Prompting & 11 & 23.91 \\
\hline & Appealing & 8 & 17.39 \\
\hline & Giving up & 0 & 0.00 \\
\hline & Total & 46 & 100.00 \\
\hline
\end{tabular}


In conversation with a female guest, Kate Hudson, Jimmy only used clean start, uptakes, links, alert, filled pause, silent pause, prompting and appealing. For instance, he appliedthe alert strategy in taking the turn:

(4) Jimmy: yeah it looks cool you did it for a role

Kate: I did I did a film with sia and

Jimmy: -OH SIA directed a film right

Jimmy cut off Kate's utterance right after she mentioned Sia's name to make sure that Sia, who is a famous singer, also directed a film. Interrupting someone's utterances with high pitch that showed in the conversation above can be classified as alert strategy.

In holding the turn, the example is:

(5) Kate: yeah aa you know Jimmy I love pumpkin spice like I really love it just because I'm kinda those people that loves the holidays like I change my house and the scents and everything and pumpkin spice is one of the things I put it in my house I

Jimmy: -WHAT about well know that what about on pizza is it eee are you

In conversation above, Jimmy applied filled pause and verbal fillers in one utterance. Since he was going to ask a question to Kate, Jimmy maintained the floor using filled pause strategy "what about on pizza is it eee are you". He also applied "well" which is known as a verbal filler in holding the turn strategy

Furthermore, the example in yielding the turn is:

(6) Jimmy: this book is called pretty fun and it's about running a party right

Kate: well no its about I mean I mean it's about why it is important to have to gather I mean to me it's like on of of I we talked about wellness a lot we talked about healthiness people forget to talked about why we connect and that's kind of the focus on this along with the fun stuffs but it's really about its important to connect it's not about the party it's about the tradition
Jimmy gives the turn to Kate by applying appealing strategy which focused to get feedback by using the word "right"in the end of the sentence.

\section{Ellen DeGeneres' Interview with a Male Guest, Anthony Anderson}

Table 3. Frequency of Ellen DeGeneres' turn taking strategies in interview with a male guest

\begin{tabular}{|c|c|c|c|}
\hline Strategy & Substrategy & Freq. & $\%$ \\
\hline \multirow{3}{*}{$\begin{array}{l}\text { Taking } \\
\text { the turn }\end{array}$} & Starting up & 3 & 11.54 \\
\hline & Taking over & 4 & 15.38 \\
\hline & Interrupting & 2 & 7.69 \\
\hline \multirow{4}{*}{$\begin{array}{l}\text { Holding } \\
\text { the turn }\end{array}$} & $\begin{array}{l}\text { Filled } \\
\text { pause/Verbal } \\
\text { fillers }\end{array}$ & 7 & 26.92 \\
\hline & Silent pause & - & - \\
\hline & $\begin{array}{l}\text { Lexical } \\
\text { repetition }\end{array}$ & 1 & 3.85 \\
\hline & A new start & 1 & 3.85 \\
\hline \multirow{4}{*}{$\begin{array}{l}\text { Yielding } \\
\text { the turn }\end{array}$} & Prompting & 7 & 26.92 \\
\hline & Appealing & 1 & 3.85 \\
\hline & Giving up & - & - \\
\hline & Total & 26 & 100.00 \\
\hline
\end{tabular}

In her conversation with male guest, Ellen performed hesitant start, clean start, uptakes, links, alert, filled pause/verbal fillers, lexical repetition, a new start, prompting and appealing.

In taking the turn, she applied clean start strategy which shown below:

(7) Anthony: yes little tiny shots that I thought was water I thought they were joking until I hit that and then that got me started for the night

Ellen: right

Anthony: yes

Ellen: well if you want more ((spotted some alcohols))

An example of holding the turn is shown below:

(8) Anthony: I can't afford you

Ellen: ((laughing)) alright let's talk about aaa let's talk about black is haaa the season 
premiere is tomorrow and aa so aa this is the musical tomorrow, right

This utterance contains two strategies in holding the turn; lexical repetition strategy and new start strategy.

To yield the turn, she used prompting strategy

(9) Ellen: how do you lose maybach

Anthony: aa tequila

Ellen questioned how Anthony lost his Maybach. Jokingly, Anthony answered by saying "tequila" which means he was drunk. However, it was just a joke. As mentioned before, the characteristic of prompting strategy is by asking questions.

\section{Ellen DeGeneres' Interview with a Female Guest, Kate Hudson}

Table 4. Frequency of Ellen DeGeneres' turn taking strategies in interview with a female guest

\begin{tabular}{|c|c|c|c|}
\hline Strategy & Substrategy & Freq. & $\%$ \\
\hline \multirow{3}{*}{$\begin{array}{l}\text { Taking } \\
\text { the turn }\end{array}$} & Starting up & 3 & 5.66 \\
\hline & Taking over & 11 & 20.75 \\
\hline & Interrupting & 2 & 3.77 \\
\hline \multirow{4}{*}{$\begin{array}{l}\text { Holding } \\
\text { the turn }\end{array}$} & $\begin{array}{l}\text { Filled } \\
\text { pause/Verbal } \\
\text { fillers }\end{array}$ & 9 & 16.98 \\
\hline & Silent pause & 1 & 1.89 \\
\hline & $\begin{array}{l}\text { Lexical } \\
\text { repetition }\end{array}$ & 9 & 16.98 \\
\hline & A new start & 3 & 5.66 \\
\hline \multirow{4}{*}{$\begin{array}{l}\text { Yielding } \\
\text { the turn }\end{array}$} & Prompting & 11 & 20.75 \\
\hline & Appealing & 2 & 3.77 \\
\hline & Giving up & 2 & 3.77 \\
\hline & Total & 53 & 100.00 \\
\hline
\end{tabular}

Ellen, as the representative of female presenters, performed hesitant start, clean start, uptakes, links, alert, filled pause/verbal fillers, silent pause, lexical repetition, a new start, prompting, appealing, and giving up in her conversation with female guest. One of the examples in taking the turn is provided below:

(10) Ellen: Danny and everybody likes the hair Kate: yeah
Ellen: because some guys don't like women with short hair I mean

Ellen was taking the turn by using the conjunction "because". Starting the turn by applying conjunction in the beginning of the utterance is called links strategy.

In holding the turn, she used lexical repetition as shown below:

(11) Ellen: [now] says it'skatehudson appears fun flirty fit $\mathrm{AF}$ aa and aa how does she do it but next to you it says get great ass so it acts its look like its look like this is how you get it but your story is up here

Kate: gosh it sad you know advertising I guess

Furthermore, the examples of yielding the turn that had been used by Ellen used the giving up substrategy as part of the yielding the turn strategy. Here is an example:

(12) Ellen: and so your boys and your mm you have a new boyfriend his name is $(0.3)$

\section{Kate: Danny}

Ellen yielded the turn by using giving up strategy which indicated by the use of long pause in the end of the utterance.

After identifying the findings, there are similarities between the two presenters in performing the turn-taking strategies. As we know, Jimmy Kimmel Live! and Ellen DeGeneres Show is an informal talk show. This is so, metacomment strategy was not being applied by both presenter to hand over the turn to the guests. Additionally, prompting strategy was mainly used by both presenters since a talk show requires the presenters to ask questions to the guest. Meanwhile, Ellen performed giving up strategy but only to the female guest. This strategy also never been used by Jimmy Kimmel to his male or female guest.

According to Faizah (2016), female speakers are more inclined to interrupt same-sex speakers and male speakers are more inclined to interrupt opposite-sex speakers. This is related to the prominent research by Zimmerman and West (1978) that men interrupted more in mixed-sex conversation. In this study, it was also found that Jimmy, as the representative of male presenters, did many interruptions in his conversation with the 
female presenter, Kate Hudson. According to the findings, he used the alert strategy 16 times while talking with Kate Hudson, but only performed 3 times in his conversation with the male guest, Anthony Anderson. As mentioned before, an alert strategy is used when someone cuts off the ongoing talk in a high pitch. Compared to the representative of female presenters, Ellen only performed the alert strategy twice in each conversation with male and female guests. Hence, in line with the idea of violation in turn-taking related to gender study proposed by Coates (2013), this study also proved that male interrupted more in mixed-sex conversation compared to women.

\section{CONCLUSION}

The results showed that in conversation between the male presenter Jimmy Kimmel and the male guest Anthony Anderson, it showed that Jimmy applied several strategies in taking the turn such as hesitant start, clean start, uptakes, links and alert. To hold the turn, he used all the substrategies namely filled pause/verbal fillers, silent pause, lexical repetition, and a new start. Furthermore, prompting and appealing were also used by Jimmy to yield his turn. Meanwhile, in conversation between Jimmy and the female guest Kate Hudson, the result showed that Jimmy used clean start, uptakes, links and alert in taking the turn. In holding the turn, he used filled pause and silent pause strategy. And to yield the turn, he applied prompting and appealing strategies.

Then, after analyzing the conversation between the female presenter Ellen DeGeneres and the male guest Anthony Anderson, the result showed that Ellen also performed several strategies in taking the turn, holding the turn, and yielding the turn. She used hesitant start, clean start, uptakes, links, and alert. While maintaining the floor, she applied filled pause/verbal fillers, lexical repetition, and a new start strategy. Then, to give the turn to the guest, she employed prompting and appealing strategies. Ellen also performed several turn-taking strategies in her conversation with female guest, Kate Hudson. In taking the turn, she applied hesitant start, clean start, uptakes, links, and alert. After that, she also employed all the strategies in holding the turn, such as filled pause/verbal fillers, silent pause, lexical repetition, and a new start. Finally, she also used prompting, appealing, and giving up strategies. From the explanation above, it can be concluded that both male and female presenters did not use metacomment strategy in taking the turn, since both talk shows was in informal situation. Beside that, both male and female presenters also used prompting as the main strategy to yield the turn to the guests. The differences were also found in the strategies that used by both male and female presenters. In brief, Jimmy as the male presenter never employed giving up strategy in his conversation but Ellen as the female presenter applied this strategy in her conversation with female guest named Kate Hudson.

Related to gender and language, in mixed-sex conversation, Jimmy did interruption more to Kate Hudson rather than in other conversations which relatable to the theory of Zimmerman and West (1975) stated that men interrupted more in mixedsex conversation rather than women.

\section{ACKNOWLEDGMENTS}

I am deeply grateful to $I b u$ Dr. Mirjam Anugerahwati, M. A., and Ibu Dr. Hj. Emalia Iragiliati, M.Pd, as my advisors who always patiently guided me and patiently gave their time to examine this project. I would also like to extend my gratitude to the anonymous reviewer for the insightful comments and suggestions.

\section{REFERENCES}

Abdelrahim, N. M. (2006). Turn taking behavior and gender references in speech: A case study of a group of educated Sudanese.

(Unpublished thesis). University of Khartoum, Khartoum, Sudan.

Berry, A. (1994). Spanish and American turn-taking styles: A comparative study. Pragmatics and Language Learning, monograph series, 5, 180190. 
Beattie, G. W. (1982). Turn-taking and interruption in political interviews: Margaret Thatcher and Jim Callaghan compared and contrasted.

Semiotica, 39(1-2), 93-114.

Coates, J. (2013). Women, men, and language. New York: Routledge.

Drew, Paul (2004). Conversation analysis. In K. L. Fitch, \& R. E. Sanders (Eds.), Handbook of language and social interaction (pp. 71-102). London: Laurence Erlbaum.

Eakins, B. W., \& Eakins. C. (1979). Verbal turntaking and exchanges in faculty dialogue. In B. L. Dubois \& I. Crouch (Eds.), The sociology of the languages of American women (53-62). San Antonio: Trinity University Press.

Eckert, P. \& McConnell-Ginet, S. (2003). Language and gender. Cambridge: Cambridge University Press.

Elbytra, B. (2014). Conversational analysis of language used by genders in Will Smith's "Hitch" movie. Language Horizon 2(1), 1-8.

Faizah, I. (2015). A study of interruption and overlap in male-female conversation in the talk show Mata Najwa. (Unpublished Thesis). Universitas Pendidikan Indonesia, Bandung, Indonesia.

Fishman, P. M. (1983). Interaction: the work women do. In B. Thorne, C. Kramarae, \& N. Henley (Eds), Language, gender and society (pp. 89-101). London: Newbury House.

Ghilzai, S. A. \& Baloch, M. (2016). Conversational analysis of turn-taking behavior and gender references in multimodal conversation. Perspectives in Language, Linguistics and Media 1, 1-13.

Gunnarsson, B. (1997). Women and men in the academic discourse community. In K. Helga, \& R. Wodak (Eds.), Communicating gender in context (pp. 219-248). Amsterdam: John Benjamins.

Heath, C. and Luff, P. (1993). Explicating face-toface interaction. In N. Gilbert (Ed.), Researching social life (pp. 306-326). London: Sage.
Herring, S., Johnson, D. A. \& DiBenedetto, T. (1995). "This discussion is going too far!": Male resistance to female participation on the Internet. In K. Hall \& M. Bucholtz (Eds.), Gender articulated: Language and the socially constructed self(pp. 67-96). New York: Routledge.

Holmes, J. (1995). Women, men and politeness. London: Longman.

Hutchby, I. (2006). Media talk: Conversation analysis and the study of broadcasting. Glasgow: Open University Press.

Laskowski, K., Ostendorf, M., \& Schultz, T. (2008). Modeling vocal interaction for textindependent participant characterization in multi-party conversation. Proceedings of the $9^{\text {th }}$ SIGdial workshop on discourse and dialogue, 148-155.

Leet-Pellegrini, H. M. (1980). Conversational dominance as a function of gender and expertise. In H. Giles, W. P. Robinson \& P. M. Smith (Eds.), Language: Social Psychological Perspectives (pp. 97-104). Oxford: Pergamon Press.

Liddicoat, A. J. (2007). An Introduction to Conversation Analysis. London: Continuum.

Maghrida, A. C. (2016). A study on gender based turn taking in the conversation of the main characters in Before Midnight Film. (Unpublished Thesis). Universitas Brawijaya, Malang, Indonesia.

Mulac, A. Wiemann, J. M., Widenmann, S. J. \& Gibson, T. W. (1988). Male/female language differences and effects in same-sex and mixedsex dyads: the gender linked language effect, Communication Monographs 55(4): 315-335.

Sacks, H., Schegloff, E. A., \& Jefferson, G. (1974). A symplest Sistematics for the organization of turn taking for conversation. Language, 50, pp. 696-735.

Schick Case, S. (1988). Cultural differences, not deficiencies: an analysis of managerial women's language. In S. Rose \& L. Lawood (Eds.), Women's careers: Pathways and pitfalls (pp. 41-63). New York: Praeger. 
Strenstrom, A. B. (1994). An introduction to spoken interaction. London: Longman.

Swacker, M. (1975). The sex of the speaker as a sociolinguistic variable. In $\mathrm{B}$. Thorne \& $\mathrm{N}$. Henley (Eds.), Language and sex (pp. 76-83). Rowley, MA: Newbury House.

Tannen, Deborah. (1992). You just don't understand: women and men in conversation. London: Virago.
West, C. (1998). When the doctor is a 'lady': power, status and gender in physician-patient encounters. In J. Coates (Ed.), Language and gender: $A$ reader (pp. 396-412). Oxford: Blackwell.

Zimmerman, D. and West, C. (1975) Sex roles interruptions and silences in conversations. In B. Thorne \& N. Henley (Eds.), Language and Sex: Difference and Dominance. Rowley, MA: Newbury House. 